British Journal of Psychiatry (1996), 168, 250-254

\title{
Correspondence
}

Contents: The validity of evidence/Lithium revisited/ Season-of-birth and "age incidence" effects/ Anorexia nervosa rates - conclusions for the wrong reasons/Periodic psychosis of puberty/Treatment of PTSD/SSRI and sympathomimetic interaction

\section{The validity of evidence}

SIR: Moncrieff (1995) presents a welcome reappraisal of the experimental evidence of the efficacy of lithium in preventing relapse in manic depressive illness. A number of serious methodological problems are highlighted among these studies, including lack of blinding (of both experimenter and subject), unequal treatments of placebo and lithium groups and a failure to analyse on an 'intention to treat' basis. Rather than being a series of 'small points' as suggested by Goodwin in the accompanying commentary, these methodological flaws seriously call into question the validity of the evidence. Lack of blinding alone has recently been demonstrated to bias study results by producing spuriously exaggerated treatment effects (Schulz et al, 1995). The studies presented are both seriously methodologically flawed and mostly of such small size as to be considered invalid evidence in themselves. Meta-analysis of these studies would be difficult to justify due to their methodological heterogeneity.

MoNCRIEF, J. (1995) Lithium revisited: A re-examination of the placebo controlled trials of lithium prophylaxis in manicdepressive disorder. British Journal of Psychiatry. 167, 569-574.

Schulz, K. F., Chalmers, I., Hayes, R., et al (1995) Dimensions of methodological quality associated with estimates of treatment effects in controlled trials. Journal of the American Medical Association, 273, 408-412.

High Royds Hospital

S. GILBODY

Menston LS29 6AQ

\section{Lithium revisited}

SIR: The review of the lithium prophylaxis literature which Moncrieff (1995) has written is marred by her failure to quote and discuss papers that take a view which differs from her own. She quotes, for example, the criticism by Blackwell \& Shepherd (1968) of the open study by Baastrup \& Schou
(1967) but fails to quote and discuss the rebuttal of that criticism (Baastrup \& Schou, 1968). In her review of prospective studies Moncrieff considers observer bias and non-blindness due to side-effects likely explanations of the findings, but she fails to quote and discuss a paper which compared recurrence rates under double-blind and under non-blind conditions and found no difference (Schou et al, 1970). In her review of discontinuation studies Moncrieff considers the higher rate of recurrences in the placebo groups than in the lithium groups probably caused by withdrawal of lithium (in spite of her belief that lithium has no prophylactic action while given) rather than indication of a recurrencepreventive effect of lithium. She fails, however, to quote and discuss a paper which compared recurrence rates before lithium and after withdrawal of lithium and found no evidence of rebound (Schou et al, 1970; c.f. also Schou, 1993a). In her reference to naturalistic studies Moncrieff fails to quote and discuss a paper analysing and commenting on such studies (Schou, 1993b).

Moncrieff concludes that the placebo-controlled trials have failed to prove lithium maintenance treatment an efficacious prophylactic procedure. A review based on less biased selection of references might have led to a different conclusion.

BMAstruP, P. C. \& SChou, M. (1967) Lithium as a prophylactic agent: its effect against recurrent depressions and manic depressive psychosis. Archives of General Psychiatry, 16, 162-172.

- (1968) Prophylactic lithium. Lancet, i, 1419-1422.

Blackwell, B. \& ShepherD, M. (1968) Prophylactic lithium: another therapeutic myth? Lancet, i, 968-971.

MoNCRIEFF, J. (1995) Lithium revisited: a re-examination of the placebo-controlled trials of lithium prophylaxis in manicdepressive disorder. British Journal of Psychiatry, 167, 569-574.

SCHOU, M. (1993a) Is there a lithium withdrawal syndrome? An examination of the evidence. British Journal of Psychiatry, 163, 514-518.

- (1993b) Lithium prophylaxis: about 'naturalistic' or 'clinical practice' studies. Lithium, 4, 77-81.

-, Thomsen, K. \& BAastrup, P. C. (1970) Studies on the course of recurrent endogenous affective disorders. International Pharmacopsychiatry, 5, 100-106.

The Psychiatric Hospital

M. Schou

\section{Skovagervej, DK-8240 Risskov}

\section{Denmark}

